\title{
RADIOCARBON CONCENTRATION IN THE ATMOSPHERE AND MODERN TREE RINGS IN THE KRAKÓW AREA, SOUTHERN POLAND
}

\author{
Andrzej Rakowski ${ }^{1,2,3} \cdot$ Tadeusz Kuc $^{4}$ • Toshio Nakamura ${ }^{1}$ Anna Pazdur ${ }^{3}$ \\ ABSTRACT. New results of radiocarbon concentration in tree rings from the Kraków region covering a growth period of \\ $20 \mathrm{yr}$ have been analyzed, and the relationship between them and ${ }^{14} \mathrm{C}$ concentrations in the atmospheric $\mathrm{CO}_{2}$ are described. \\ This enabled assessment of the uptake period for pine trees at the regional climatic conditions. Both sets of data show lower \\ ${ }^{14} \mathrm{C}$ concentrations than reported for "clean air" at the reference station, indicating a remarkable input of "dead" $\mathrm{CO}_{2}$ of fossil \\ fuel origin. Using data of carbon dioxide and ${ }^{14} \mathrm{C}$ concentrations from Schauinsland, summer values of the fossil component \\ $\left(\mathrm{C}_{\mathrm{f}}\right)$ in carbon dioxide were calculated for the Kraków area. Fitting exponential and linear functions to experimental data, the \\ exchange time was calculated, and expected future ${ }^{14} \mathrm{C}$ concentration in the atmosphere was estimated.
}

\section{INTRODUCTION}

Recently, atmospheric concentration of carbon dioxide has exceeded 370 ppm (Keeling et al. 1995; GLOBALVIEW- $\mathrm{CO}_{2}$ 2003), mainly due to the emission of $\mathrm{CO}_{2}$ from fossil fuels such as coal, natural gas, and petroleum. This increase has affected global radiocarbon concentration in the atmosphere, as well as in the ocean and biosphere. Due to atmospheric nuclear bomb tests, ${ }^{14} \mathrm{C}$ concentration in atmospheric $\mathrm{CO}_{2}$ increased rapidly through the 1950 s and 1960 s to a maximum in 1963 , when the measured level was double the natural value (Nydal and Lövseth 1996). Since the atomic test ban treaty was enforced, the concentration of ${ }^{14} \mathrm{C}$ in the atmosphere has slowly decreased; however, in the 1990s, the concentration was still about 10\% higher than pre-bomb levels (McNeely 1994; Levin and Kromer 1997). Several laboratories in Europe are continuously monitoring atmospheric $\mathrm{CO}_{2}$ and/or carbon isotope composition, either directly (Levin and Kromer 1997; NOAA 2001; Necki et al. 2002; Kuc et al. 2003) or in plants (McNeely 1994; Krajcar Bronić et al. 1998; Rakowski et al. 2001). Results show that heavy local emissions of carbon dioxide from fossil fuels cause remarkable disturbances in carbon isotope composition in the local atmosphere and biosphere, and also have an influence on a regional and global scale. This effect is observed not only in heavily industrialized areas but also in urbanized regions where carbon dioxide is emitted from small industrial facilities, vehicles, and other common sources. The magnitude of the effect on ${ }^{14} \mathrm{C}$ concentration is dependent on the distance from the sources of $\mathrm{CO}_{2}$ emissions (Awsiuk and Pazdur 1986).

Kraków $\left(50^{\circ} 3^{\prime} \mathrm{N}, 19^{\circ} 54^{\prime} \mathrm{E}\right)$ is a city of 1 million people, located about $100 \mathrm{~km}$ to the north of the Tatra Mountains in southern Poland (Figure 1). Air pollution related to the urban infrastructure, industrial facilities, and a large steel factory (Huta im. Tadeusza Sendzimira) has elevated carbon dioxide levels in the local atmosphere (Kuc et al. 2003). Since 1983, the Department of Environmental Physics, University of Science and Technology in Kraków has monitored carbon isotope compositions in tropospheric $\mathrm{CO}_{2}$ (Florkowski et al. 1975; Kuc 1991; Kuc and Zimnoch 1998). Samples were taken at biweekly intervals from the Faculty building roof on the university campus, $25 \mathrm{~m}$ above ground level. Annual tree rings were also taken from pine trees (Pinus sylvestris) growing near the university.

\footnotetext{
${ }^{1}$ University of Nagoya, Center for Chronological Research, Nagoya, Japan.

${ }^{2}$ Corresponding author. Email: rakowski@zeus.polsl.gliwice.pl.

${ }^{3}$ Silesian University of Technology, Institute of Physics, Radiocarbon Laboratory, Gliwice, Poland.

${ }^{4}$ AGH, University of Science and Technology, Kraków, Poland.
} 


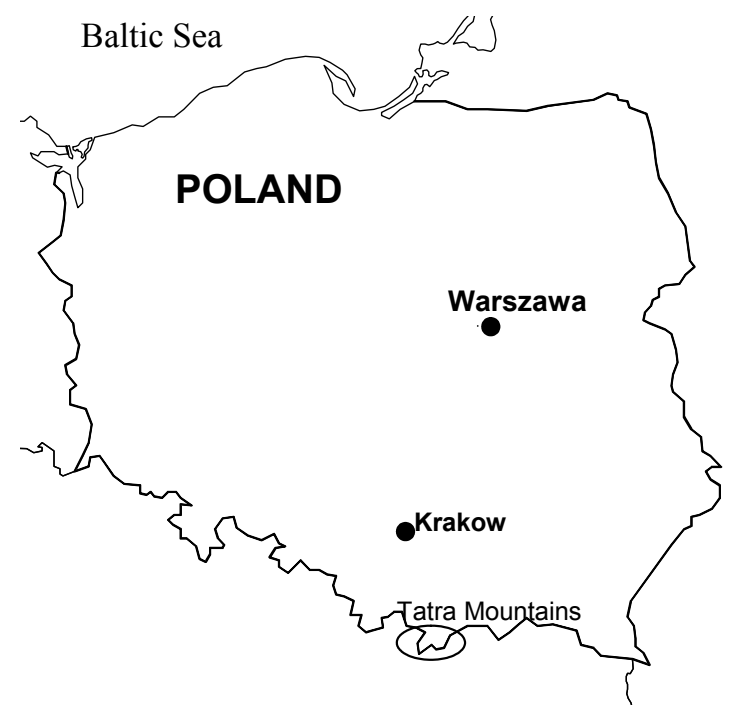

Figure 1 Map of Poland with the location of Kraków

\section{SAMPLES AND METHODS}

In this study, 2 kinds of samples were used: $\mathrm{CO}_{2}$ separated directly from the air at over sequential 2-week intervals and representing an integrated value over the sampling period, and tree rings obtained from trunks of pine trees (Pinus sylvestris) growing near the university.

\section{Atmospheric $\mathrm{CO}_{2}$ Samples}

Samples of atmospheric $\mathrm{CO}_{2}$ were taken by applying the method of selective sorption in capillary sorbent, as described in Florkowski et al. (1975), Kuc (1991), and Kuc and Zimnoch (1998). ${ }^{14} \mathrm{C}$ measurements were performed with a liquid scintillation spectrometer (Tri-Carb ${ }^{\circledR}$, Canberra-Packard) after the conversion of purified $\mathrm{CO}_{2}$ to benzene using a standard procedure and mixing with a scintillation cocktail (b-PBD + b-MSB, Packard). Stable carbon isotope composition was measured using VG Micromass $602 \mathrm{C}$ and Finningan MAT Delta S mass spectrometers at Kraków University.

\section{Tree-Ring Samples}

Annual growth rings in pine trees were sampled with a hollow drill. In order to obtain sufficient material for accelerator mass spectrometry (AMS) analysis, 3 core samples were taken from the tree and annual growth rings were separated. Samples were washed in distilled water and prepared following the standard AAA procedure. Each sample was heated at $80^{\circ} \mathrm{C}$ in $0.5 \mathrm{M} \mathrm{HCl}$ for $12 \mathrm{hr}$, then filtered, rinsed, and heated in $0.1 \mathrm{M} \mathrm{NaOH}\left(80^{\circ} \mathrm{C}, 12 \mathrm{hr}\right)$. The samples were then filtered, rinsed, and heated again in $0.5 \mathrm{M} \mathrm{HCl}\left(80^{\circ} \mathrm{C}, 12 \mathrm{hr}\right)$, then re-filtered, rinsed in distilled water, and dried. Sample residues were combined with cupric oxide, sealed in glass tubes, and evacuated by a rotary pump. The tubes were then placed in an electric furnace for $2 \mathrm{hr}$ at $850^{\circ} \mathrm{C}$. Carbon dioxide produced from the samples was purified in a glass cryogenic vacuum-line system. Water produced during combustion was removed via a trap containing a mixture of methanol and liquid nitrogen at $180{ }^{\circ} \mathrm{K} . \mathrm{SO}_{\mathrm{x}}$ compounds were removed with an $n$-pentane trap cooled by liquid nitrogen. $\mathrm{Pure}^{\mathrm{CO}_{2}}$ was then condensed in glass tubes at liquid nitrogen temperatures. The prepared $\mathrm{CO}_{2}$ samples were reduced to graphite using iron powder as a catalyst (Kitagawa et al. 1993). The iron powder was prepared in a 
vacuum line containing hydrogen and heated for about $1 \mathrm{hr}$ at $450{ }^{\circ} \mathrm{C}$. The line was evacuated and $\mathrm{CO}_{2}$ was condensed with the iron powder using liquid nitrogen. Hydrogen was then added and the glass tube was sealed. Reduction was done in an electric furnace at $650{ }^{\circ} \mathrm{C}$ for $6 \mathrm{hr}$. The resulting mixture of graphite and iron powder was dried and pressed into the target holder of the AMS system. The $\Delta^{14} \mathrm{C}$ and $\delta^{13} \mathrm{C}$ values were measured using a HVEE Tandetron AMS system and a Finningan MAT 252 mass spectrometer, respectively, at the Center for Chronological Research, Nagoya University, Japan (Nakamura et al. 2000).

${ }^{14} \mathrm{C}$ data are reported in terms of $\Delta{ }^{14} \mathrm{C}$ (in \%) deviations from the standard sample, $95 \%$ activity of NBS oxalic acid (Stuiver and Polach 1977). Stable carbon isotope data are expressed in $\delta$-notation on the PDB scale (Craig 1957).

\section{RESULTS AND DISCUSSION}

${ }^{14} \mathrm{C}$ concentrations in tree rings and atmospheric $\mathrm{CO}_{2}$ from the Kraków area are shown in Figure 2, together with data from Schauinsland (Levin and Kromer 1997) as reference values. In order to compare results obtained for tree rings and atmospheric $\mathrm{CO}_{2},{ }^{14} \mathrm{C}$ concentration data in atmospheric $\mathrm{CO}_{2}$ were averaged for the April to September period of each year, which is the season of vegetative growth and $\mathrm{CO}_{2}$ uptake in Poland, and corrected to $\delta^{13} \mathrm{C}=-25 \%$ to provide the $\Delta^{14} \mathrm{C}$ notation (Stuiver and Polach 1977). Data from Schauinsland (Levin and Kromer 1997) presented in the $\Delta^{14} \mathrm{C}$ notation were fitted to an exponential curve. ${ }^{14} \mathrm{C}$ concentration for $1997-2002$ were estimated by extrapolation on the curve. All data show a gradual decrease of ${ }^{14} \mathrm{C}$ activity over time. Decreases of $7.1 \%$ per yr for tree rings and $9.15 \%$ per yr for atmospheric ${ }^{14} \mathrm{C}$ were obtained. Atmospheric $\Delta^{14} \mathrm{C}$ values measured at 2 stations in Croatia (Zagreb and Plitovice) during the same period decrease at rates of $12 \%$ and $10.6 \%$ per yr, respectively (Krajcar Bronić et al. 1998). For the Schauinsland station, decreases of 14.1\%o per yr for the 1983-1985 period and 9.7\%o per yr for 1985-1989 were reported (Levin et al. 1992).

Absolute differences between $\Delta^{14} \mathrm{C}$ values from tree rings and atmospheric $\mathrm{CO}_{2}$ from the Kraków area are presented in bar form in Figure 2. ${ }^{14} \mathrm{C}$ concentrations in atmospheric $\mathrm{CO}_{2}$ show strong peakto-peak ( $56 \%$, Kuc and Zimnoch 1998) and seasonal fluctuations that are not recorded in the treering samples. ${ }^{14} \mathrm{C}$ concentrations in both kinds of samples from Kraków are lower than in "clean air" at the Schauinsland station. This is attributed to a local Suess effect. The $\Delta^{14} \mathrm{C}$ values in tree rings (108\%o, 99\%o, and $85 \%$ for 1994,1995 , and 1996 , respectively) are lower than the mean yearly values in atmospheric $\mathrm{CO}_{2}$ at Schauinsland $(117 \%, 111 \%$, and $102 \%$, respectively; Levin and Kromer 1997) but higher than those measured in Zagreb (81\%, 88\%, and 56\%; Krajcar Bronić et al. 1998) for the same period.

Exponential curves were fitted to the Kraków data for the period of 1983-2002 to determine longterm changes in ${ }^{14} \mathrm{C}$ concentration in the atmosphere and biosphere. These analyses provide time decay constants of $16.7 \mathrm{yr}$ for tree-ring data and $14.3 \mathrm{yr}$ for atmospheric $\mathrm{CO}_{2}$, which correspond well with 16-yr estimates reported in the literature (Levin et al. 1995; McNeely 1994; Krajcar Bronić et al. 1998). Carbon isotope ratios calculated from exponential and linear models decrease at rates of $7.1 \%$ and $6.75 \%$ per yr, respectively, for tree-ring data, and $7.75 \%$ and $6.29 \%$ per yr for atmospheric $\mathrm{CO}_{2}$ data. According to the linear model, $\Delta^{14} \mathrm{C}$ is estimated to equal $0 \%$ in 2010 for tree rings and 2007 for atmospheric $\mathrm{CO}_{2}$. The same procedure produces estimates of 2007 for the Schauinsland data (Levin and Kromer 1997) and 2004 for the Groningen data (Meijer et al. 1995).

${ }^{14} \mathrm{C}$ concentration in the atmosphere over large cities is strongly affected by emissions of $\mathrm{CO}_{2}$ from fossil fuels. Concentrations of carbon dioxide can be divided into 3 components: a background com- 


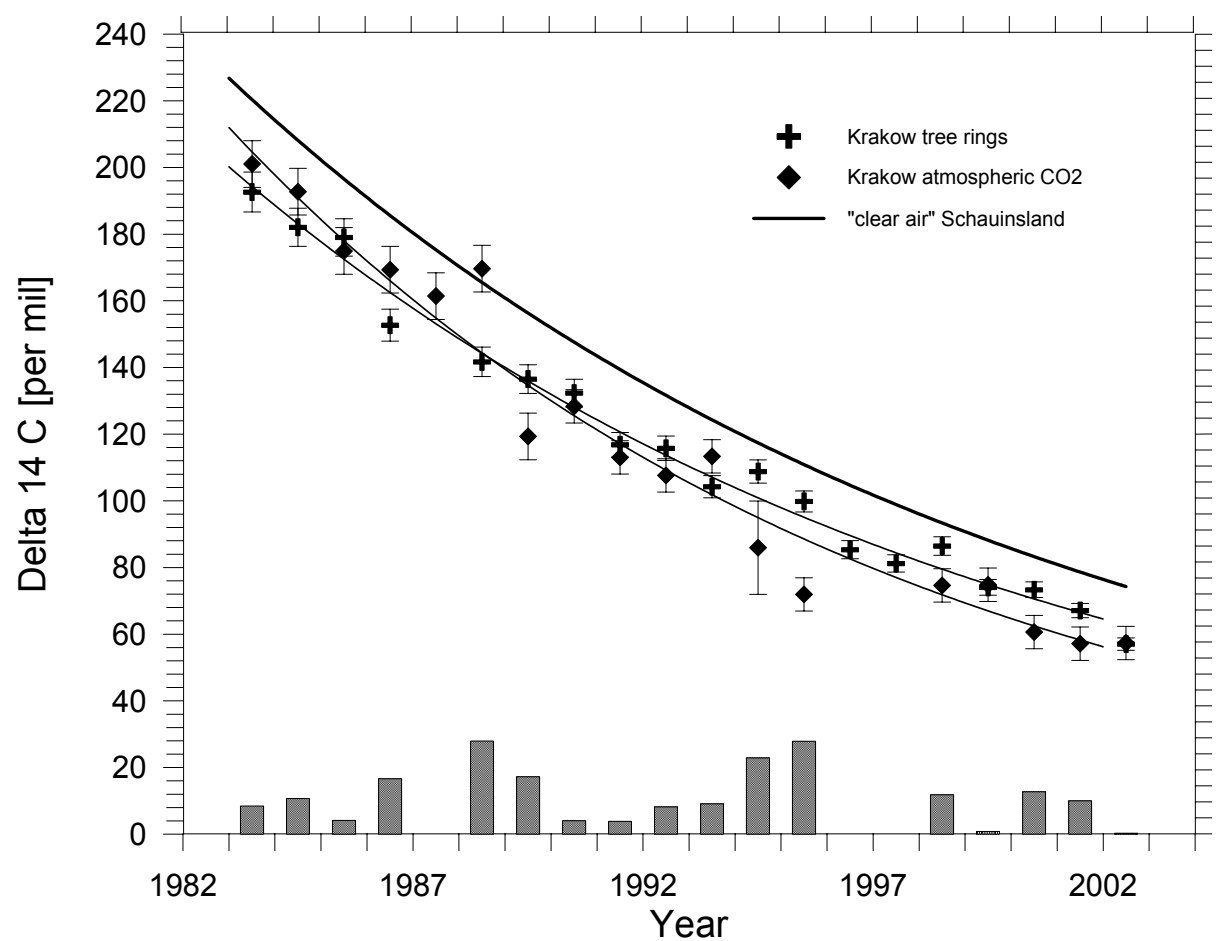

Figure $2 \Delta^{14} \mathrm{C}$ values in tree rings and atmospheric $\mathrm{CO}_{2}$ samples collected in the Kraków area, southern Poland. The solid line represents ${ }^{14} \mathrm{C}$ concentration in "clear air" at Schauinsland station, estimated from the measurement of atmospheric $\mathrm{CO}_{2}$ (Levin and Kromer 1997). Bars show absolute differences between atmospheric $\mathrm{CO}_{2}$ and tree-ring samples for Kraków. All atmospheric data represent mean annual values for the April to September season, expressed as $\Delta^{14} \mathrm{C}$.

ponent $\left(\mathrm{C}_{\mathrm{a}}\right)$, a biogenic component $\left(\mathrm{C}_{\mathrm{b}}\right)$, and a fossil component $\left(\mathrm{C}_{\mathrm{f}}\right)$. Mathematical equations that can describe the relationships between each component and carbon isotopic composition are discussed in previous literature (e.g. Levin et al. 1989; Zondervan and Meijer 1996; Kuc et al. 2003), and were used to calculate $C_{f}$ for the Kraków data. The value of $C_{f}$ varies seasonally, from $\sim 27.5 \mathrm{ppmv}$ in the winter to $\sim 10 \mathrm{ppmv}$ in the summer during the 1983-1994 period (Kuc and Zimnoch 1998; Kuc et al. 2003). This variation correlates with differences in fossil fuel consumption between the seasons in the Kraków area.

New estimates of $C_{f}$ using the new Kraków data are presented in Figure 3. Reference values of ${ }^{14} \mathrm{C}$ and $\mathrm{CO}_{2}$ concentration representing "clean air" were calculated using data from Schauinsland station (GLOBALVIEW-CO 2 2003). Averaging $C_{f}$ over 2 decades (1983-2003) for the April to September season, values of $5.9 \mathrm{ppmv}$ and $6.5 \mathrm{ppmv}$ were obtained for tree rings and atmospheric $\mathrm{CO}_{2}$, respectively. Both values are lower than the yearly average obtained for consecutive years by Kuc and Zimnoch (1998); however, the estimates converge over time. Lower values of $C_{f}$ observed in the Kraków area in recent years are the result of a reduction in fossil fuel consumption, especially in the case of coal. 


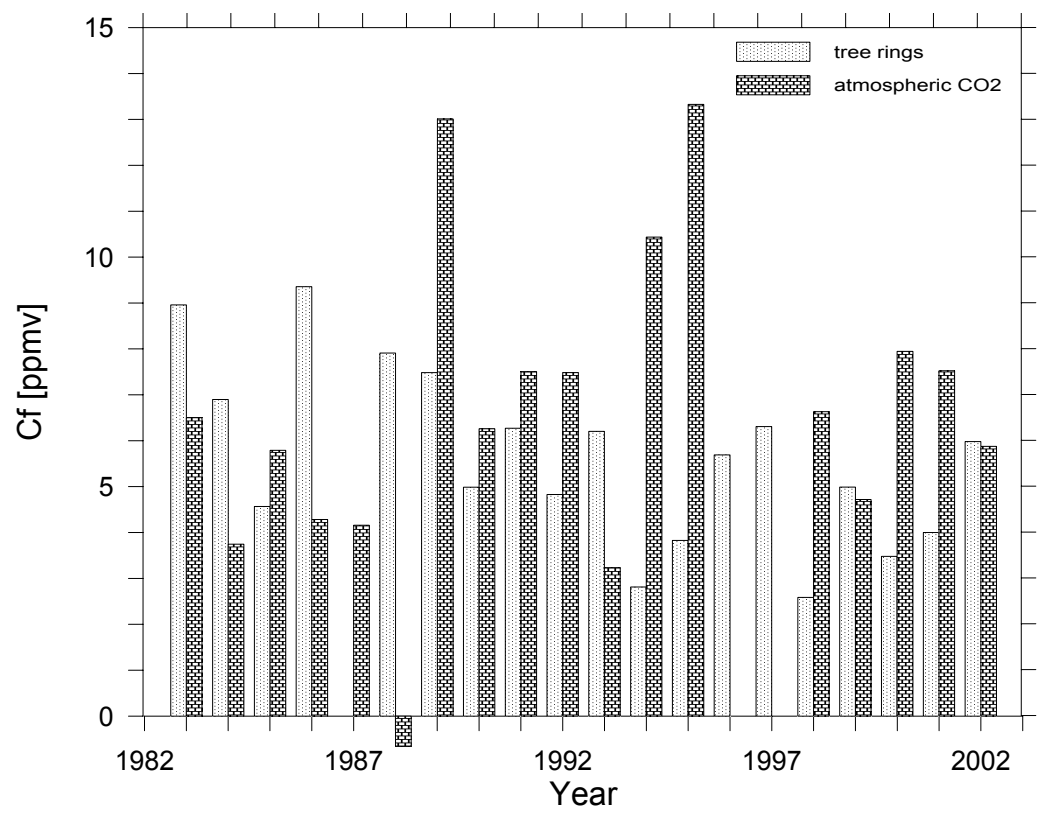

Figure 3 Values of the fossil component $\mathrm{C}_{\mathrm{f}}$ calculated using tree-ring and atmospheric $\mathrm{CO}_{2}$ data from the Kraków sampling site. Data represent mean annual values for the April to September season.

\section{CONCLUSION}

${ }^{14} \mathrm{C}$ concentration in samples of tree rings and in atmospheric $\mathrm{CO}_{2}$, measured in Kraków over last $20 \mathrm{yr}$, are lower than in "clean air" due to the input of $\mathrm{CO}_{2}$ from fossil fuels. Decreases in ${ }^{14} \mathrm{C}$ concentration of $7.1 \%$ per yr for tree rings and $9.15 \%$ per yr for atmospheric $\mathrm{CO}_{2}$ were observed. Data fitted to exponential and linear functions provided reliable estimates of rates of decrease in carbon isotope ratios and time decay constants for the sampling area. Isotopic records in tree rings and atmospheric $\mathrm{CO}_{2}$ collected over long time periods yield information on the local input of anthropogenic $\mathrm{CO}_{2}$. Moreover, tree rings appear to be a valuable archive of isotopic variations in the local environment over time, albeit in annual increments only. In comparing atmospheric $\mathrm{CO}_{2}$ and treering data, it is necessary to consider the climatic conditions of central Europe, since the commencement and duration of the vegetative growth (and $\mathrm{CO}_{2}$ uptake) period can vary from year to year.

\section{ACKNOWLEDGEMENTS}

This work was partly supported by Ministry of Education, Sciences, Sport and Culture of Japan and the Polish State Committee for Scientific Research. We express our thanks to all staff of the Center for Chronological Research, Nagoya University for help and especially to Tomoko Ohta for explaining the procedure of sample preparation for the AMS system. The authors also thank Daniel Dunkley for improving the English of the manuscript.

\section{REFERENCES}

Awsiuk R, Pazdur MF. 1986. Regional Suess effect in Upper Silesia urban area. Radiocarbon 28(2A):655-60.

Craig H. 1957. Isotope standards for carbon and oxygen and correction factors for mass-spectrometric analysis of carbon dioxide. Geochimica et Cosmochimica Acta 12:133-49.

Florkowski T, Grabczak J, Kuc T, Różański K. 1975. Determination of radiocarbon in water by gas or liquid 
scintillation counting. Nkcleonika 20(11-12):105366.

GLOBALVIEW- $\mathrm{CO}_{2}$. 2003. Cooperative Atmospheric Data Integration Project-Carbon Dioxide. CDROM, NOAA CMDL, Boulder, Colorado [Also available on internet via anonymous FTP to ftp.cmdl.noaa.gov, Path: ccg/co2/GLOBALVIEW].

Keeling CD, Whorf TP, van der Plicht J. 1995. International extremes in the rate of rise of atmospheric carbon dioxide since 1980. Nature 375:666-9

Kitagawa H, Masuzawa T, Nakamura T, Matsumoto E. 1993. A batch preparation method for graphite targets with low level background for AMS ${ }^{14} \mathrm{C}$ measurements. Radiocarbon 35(2):295-300.

Krajcar Bronić I, Horvatinčić N, Obelić B. 1998. Two decades of environmental isotope records in Croatia, reconstruction of the past and prediction of future level. Radiocarbon 40(1):399-416.

Kuc T. 1991. Concentration and carbon isotope composition of atmospheric $\mathrm{CO}_{2}$ in southern Poland. Tellus 43B:373-8.

Kuc T, Zimnoch M. 1998. Changes of the $\mathrm{CO}_{2}$ sources and sink in polluted urban area (southern Poland) over last decade, deriving from the carbon isotope composition. Radiocarbon 40(1):417-23.

Kuc T, Rozanski K, Zimnoch M, Necki JM, Korus A. 2003. Anthropogenic emissions of $\mathrm{CO}_{2}$ and $\mathrm{CH}_{4}$ in an urban environment. Applied Energy 75:193-203.

Levin I, Schuchard J, Kromer B, Münnich O. 1989. The continental European Suess effect. Radiocarbon 31(3):431-40.

Levin I, Kromer B. 1997. Twenty years of high-precision atmospheric ${ }^{14} \mathrm{CO}_{2}$ observation at Schauinsland station, Germany. Radiocarbon 39(2):205-18.

Levin I, Graul R, Trivett NBA. 1995. Long-term observations of atmospheric $\mathrm{CO}_{2}$ and carbon isotopes at continental sites in Germany. Tellus 47B:23-34.

Levin I, Bösinger R, Bonani G, Francey RJ, Kromer B,
Münnich KO, Suter M, Trivett NBA, Wölfli W. 1992. Radiocarbon in atmospheric carbon dioxide and methane: global distribution and trends. In: Taylor RE, Long A, Kra RS, editors. Radiocarbon After Four Decades: An Interdisciplinary Perspective. New York: Springer-Verlag. p 503-18.

McNeely R. 1994. Long-term environmental monitoring of ${ }^{14} \mathrm{C}$ levels in Ottawa region. Environment International 20(5):675-9.

Meijer HAJ, van der Plicht H, Gislofoss JS, Nydal R. 1995. Comparing long-term atmospheric ${ }^{14} \mathrm{C}$ and ${ }^{3} \mathrm{H}$ records near Groningen, the Netherlands with Fruholmen, Norway and Izaña, Canary Islands ${ }^{14} \mathrm{C}$ stations. Radiocarbon 37(1):39-50.

Nakamura T, Niu E, Oda H, Ikeda A, Minami M, Takahashi H, Adachi M, Pals L, Gottdang A, Suya N. 2000. The HVEE Tandetron AMS system at Nagoya University. Nuclear Instruments and Methods in Physics Research B 172:52-7.

Necki J, Schmidt M, Rozanski K, Zimnoch M, Korus A, Lasa J, Graul R, Levin I. 2002. Six-year record of atmospheric carbon dioxide and methane at a highaltitude mountain site in Poland. Tellus 55B:94-104.

NOAA Climate Monitoring and Diagnostics Laboratory. 2001. ftp site: ftp://cmdl.noaa.gov/ccg/ networek.txt.

Nydal R, Lövseth K. 1996. Carbon-14 measurement in atmospheric $\mathrm{CO}_{2}$ from Northern and Southern Hemisphere sites, 1962-1993. Oak Ridge National Laboratory NDP-057.

Rakowski AZ, Pawełczyk S, Pazdur A. 2001. Changes of ${ }^{14} \mathrm{C}$ concentration in modern trees from Upper Silesia region, Poland. Radiocarbon 43(2B):679-89.

Stuiver M, Polach HA. 1977. Discussion: reporting of ${ }^{14} \mathrm{C}$ data. Radiocarbon 19(2):355-63

Zondervan A, Meijer AJ. 1996. Isotopic characterization of $\mathrm{CO}_{2}$ sources during regional pollution events using isotopic and radiocarbon analysis. Tellus 48B:601-12. 